\title{
High Purity Nickel Recovery from an Industrial Sidestream Using Concentration and Liquid-Liquid Extraction Techniques
}

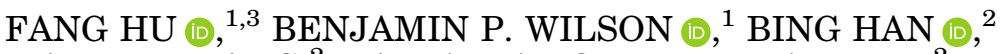 \\ JIANXIN ZHANG ${ }^{2}$ MARJATTA LOUHI-KULTANEN (D) ${ }^{2}$ \\ and MARI LUNDSTRÖM (10) \\ 1.- Hydrometallurgy and Corrosion, Department of Chemical and Metallurgical Engineering \\ (CMET), School of Chemical Engineering, Aalto University, P.O. Box 12200, 00076 Aalto, Finland. \\ 2.-Chemical Engineering in Aqueous Systems, Department of Chemical and Metallurgical \\ Engineering (CMET), School of Chemical Engineering, Aalto University, P.O. Box 16100, 00076 \\ Aalto, Finland. 3.-College of Chemistry and Chemical Engineering, Central South University, \\ Changsha 410083, Hunan, China. 4.—e-mail: mari.lundstrom@aalto.fi
}

\begin{abstract}
This article outlines an alternative flowsheet for the purification of a multimetal industrial sidestream $(16.3 \mathrm{~g} / \mathrm{l} \mathrm{Ni}, 0.7 \mathrm{~g} / \mathrm{l} \mathrm{Co}, 0.6 \mathrm{~g} / \mathrm{l} \mathrm{Ca}$ and $1.6 \mathrm{~g} / \mathrm{l} \mathrm{Mg})$ to allow high-purity nickel recovery. The methodology comprises an initial evaporation step to achieve $\mathrm{Ca}$ removal followed by impurity $(\mathrm{Ca}, \mathrm{Mg})$ and valuable $(\mathrm{Co}, \mathrm{Ni})$ element separation via two-step solvent extraction with organophosphorus extractants. Results indicate that $>80 \%$ of $\mathrm{Ca}$ is selectively removed as $\mathrm{CaSO}_{4} \cdot 2 \mathrm{H}_{2} \mathrm{O}$ by evaporation with a concentration degree $>6$. In the following treatment, $\sim 90 \%$ of residual $\mathrm{Ca}(0.6 \mathrm{~g} / \mathrm{l})$ can be selectively extracted with $\mathrm{Na}-\mathrm{D}_{2} \mathrm{EHPA}$. The subsequent solvent extraction step with Na-Cyanex 272 separates $\mathrm{Co}(>99 \%)$ and $\mathrm{Mg}(>95 \%)$. The resultant nickel sulfate solution $(61.7 \mathrm{~g} / 1 \mathrm{Ni}, 0.3 \mathrm{~g} / \mathrm{l} \mathrm{Mg}$ and $\mathrm{Co} 0.007 \mathrm{~g} / \mathrm{l})$ of $>99.5 \%$ purity can be directly integrated into state-of-the-art nickel recovery processes.
\end{abstract}

\section{INTRODUCTION}

Nickel and cobalt production is essential to ensure the smooth functionality of industrial material supply chains that range from stainless steel to batteries. Consequently, the ability to efficiently recover nickel and cobalt from industrial hydrometallurgical sidestreams, for example, can have a significant impact on the related process economics and the future sustainability of these valuable resources. ${ }^{1-3}$ Nevertheless, in such process solutions impurities such as $\mathrm{Ca}, \mathrm{Cu}, \mathrm{Mg}, \mathrm{Al}, \mathrm{Mn}$ and $\mathrm{Fe}$ are often present. As a result, it is desirable that the most valuable elements- $\mathrm{Ni}$ and $\mathrm{Co}$ - are efficiently separated from these impurities to meet the required purity demands.

It has been previously reported that nickel recovery from industrial sidestreams can be achieved by a number of hydrometallurgical-based routes such as chemical precipitation, ${ }^{4,5}$ ion exchange, ${ }^{6,7} \mathrm{mem}$ brane technology, ${ }^{8}$ solvent extraction, ${ }^{9,10}$ cooling crystallization $^{11,12}$ and electrowinning. ${ }^{13,14}$ Of these, solvent extraction (SX) has become established as a commercially viable industrial-scale unit process that allows nickel capture. ${ }^{15-17}$ For example, in the Cawse plant (Australia), after re-leaching of the nickel/cobalt hydroxide precipitate with ammonia-ammonium carbonate medium, the SX step was used to separate $\mathrm{Ni}$ with 2-hydroxy-5nonylacetophenone oxime (LIX84-I) in preference to $\mathrm{Ca}, \mathrm{Co}, \mathrm{Mg}, \mathrm{Mn}$ and $\mathrm{Zn} .{ }^{18}$ The Bulong process involved the direct extraction of $\mathrm{Ni}$ with neodecanoic acid (Versatic 10) after extraction of Co with bis(2,4,4-trimethylpentyl) phosphinic acid (Cyanex 272), while impurities- $\mathrm{Cu}, \mathrm{Zn}, \mathrm{Mn}, \mathrm{Mg}$ and $\mathrm{Ca}$-remained in the raffinates. ${ }^{19}$ More recently, Guimaraes et al. investigated the purification of nickel sulfate solution from synthetic Ni-rich solutions by SX with Cyanex 272 and mixtures of Cyanex 272 and Versatic $10 .{ }^{20}$ It was found that impurities such as $\mathrm{Zn}, \mathrm{Co}, \mathrm{Cu}$ and $\mathrm{Mn}$ could be selectively extracted using Cyanex 272, whereas preferential extraction of $\mathrm{Ca}$ and $\mathrm{Mg}$ was achieved by mixtures of Cyanex 272 and Versatic 10 . The 
same authors also evaluated the separation of $\mathrm{Ca}$ and $\mathrm{Mg}$ vs. Ni using bis(2-ethylhexyl) phosphate acid $\left(\mathrm{D}_{2} \mathrm{EHPA}\right)$ and Cyanex $272 .{ }^{21}$ In general, for complex industrial solutions, the choice of suitable process depends on how effectively and efficiently impurities can be removed while concurrently maximizing the yield and purity of the desired final products.

In the present work, a comprehensive study for purification of an industrial sidestream was explored. To allow the recovery of high-purity nickel products (rather than low-value mixed metal precipitate), the current investigation addresses issues related to the dilute and impure nature of the investigated solution as follows: (1) concentration and $\mathrm{Ca}$ removal by evaporation from the sidestream (PLS1); (2) residual $\mathrm{Ca}$ removal from the concentrated nickel-rich solution (PLS2) by the first SX step with saponified $\mathrm{D}_{2} \mathrm{EHPA}$ (Na$\mathrm{D}_{2}$ EHPA); (3) extraction of $\mathrm{Co}$ and $\mathrm{Mg}$ over $\mathrm{Ni}$ from a mixed solution (PLS5)—which is composed of the Ca-free solution (PLS3) and the scrubbing solution of the loaded $\mathrm{D}_{2}$ EHPA (PLS4) - through a second SX step with saponified Cyanex 272 (NaCyanex 272); (4) production of a purified solution (PLS6), which can be fully integrated into state-ofthe-art processes for high-purity nickel recovery. The schematic flowsheet for these various process steps is outlined in Fig. 1. Moreover, a systematic evaluation of the precipitation and separation behaviors of the metal ions at each step of the process was performed.

\section{MATERIALS AND METHODS}

\section{Materials}

The process solution (PLS1) comprised an industrial sidestream with a composition of $16.3 \mathrm{~g} / \mathrm{l} \mathrm{Ni}$, $0.7 \mathrm{~g} / \mathrm{l} \mathrm{Co}, 0.6 \mathrm{~g} / \mathrm{l} \mathrm{Ca}$ and $1.6 \mathrm{~g} / \mathrm{l} \mathrm{Mg}$ and a $\mathrm{pH}$ value of approximately 4.2. The extractants $\mathrm{D}_{2} \mathrm{EHPA}$ (97\%, Sigma-Aldrich, Germany) and Cyanex 272 (97\%, Cytec, USA) were used as reagents for the SX processes, while kerosene (97\%, Sigma-Aldrich, Germany) was used as a diluent. Sodium hydroxide (97\%, Sigma-Aldrich, Germany) and sulfuric acid (96\%, Merck, France) were used to prepare the saponification solution and the scrubbing solution, respectively. Deionized water (resistivity $\leq 18.2 \mathrm{M} \Omega . \mathrm{cm}$, Merck Millipore, Germany) was used throughout for all experiments.

\section{Concentration Studies}

Evaporation studies were conducted to remove $\mathrm{Ca}$ and concentrate the solution in preparation for the subsequent SX steps. PLS1 with an initial volume of $400 \mathrm{ml}$ was heated in a $500-\mathrm{ml}$ open glass beaker at $100 \pm 1^{\circ} \mathrm{C}$ and stirred with a magnetic stirrer apparatus (MR Hei-Connect, Heidolph Instruments, Germany) at a speed of $350 \mathrm{rpm}$. A focused beam reflectance measurement (FBRM) Particle Track system (Mettler Toledo G400, USA) that allowed the continuous in situ monitoring of chord length sizes of particles, total count rates or count rates of the different chord length fractions was used to monitor precipitation of calcium sulfate during the

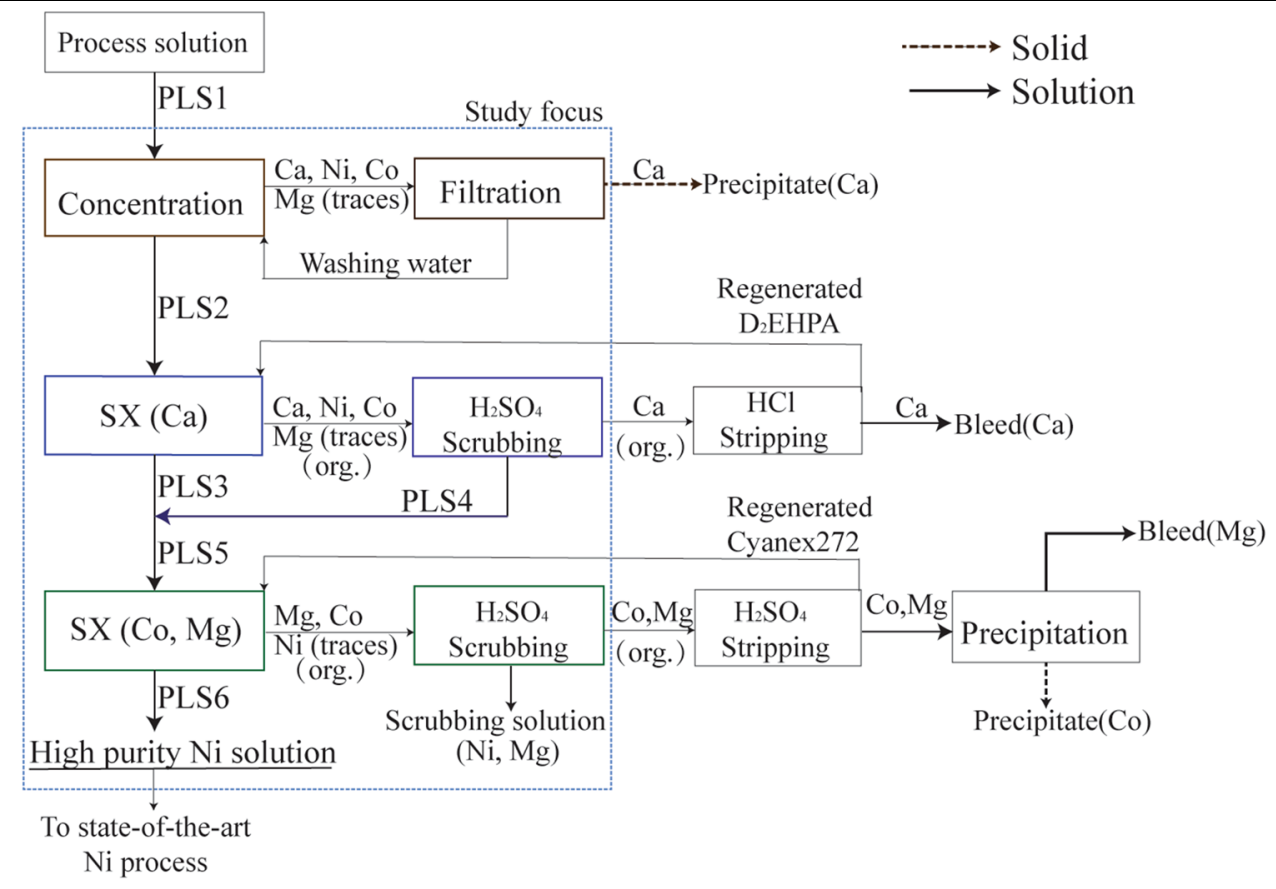

Fig. 1. Schematic flowsheet for the purification of the industrial sidestream. 
evaporation period. The probe-based Particle Track was immersed into the solution such that the particles could flow freely through the probe window. A focused laser was then utilized to produce a beam spot with a fixed rotation speed of $2 \mathrm{~m} / \mathrm{s}$ at the sapphire window to detect the presence of particles via laser light backscatter. The pulses of backscattered light were counted, and the duration of each pulse multiplied by the scan speed was used for the chord length determination. A balance (572 Kern \& Sohn $\mathrm{GmbH}$, Germany, $d=0.01 \mathrm{~g}$ ) was used to determine the mass of the PLS1 and the concentrated solutions. The volume of the concentrated solutions, $V_{r}$, could then be calculated as follows:

$$
V_{r}=V_{i}-\frac{m_{i}-m_{r}}{\rho}
$$

The concentration degree, $X_{V i / V r}$, was determined according to Eq. 2:

$$
X_{V i / V r}=\frac{V_{i}}{V_{r}}
$$

And the removal efficiency of $\mathrm{Ca}\left(R_{C a}\right)$ was calculated by Eq. 3:

$$
R_{C a}=\left(1-\frac{C_{r} \times V_{r}}{C_{i} \times V_{i}}\right) \times 100 \%
$$

where $V_{i}$ and $V_{r}$ (l) represent the volume of the PLS1 and the PLS2, respectively; $m_{i}$ and $m_{r}$ (g) are the corresponding mass of the PLS1 and the PLS2. $\rho$ is the density of water $(1.0 \mathrm{~g} / \mathrm{ml}) ; C_{i}$ and $C_{r}(\mathrm{~g} / \mathrm{l})$ are the concentration of $\mathrm{Ca}$ in the PLS1 and the PLS2, respectively.

\section{Solvent Extraction Studies}

The extractants $\mathrm{D}_{2}$ EHPA and Cyanex 272 were first diluted with kerosene and then correspondingly saponified by $10 \mathrm{M}$ and $5 \mathrm{M} \mathrm{NaOH}$ solutions prior to their use as extractants. ${ }^{22,23}$ Extraction experiments were carried out in an incubator shaker (Model KS 3000i, IKA, Germany). Equal volumes $(10 \mathrm{ml})$ of the organic and aqueous solutions were mixed in the funnels and then shaken for 10 min with a fixed shaking speed of $250 \mathrm{rpm}$ at $25 \pm 1^{\circ} \mathrm{C}$. After phase disengagement, the concentrations of $\mathrm{Ni}, \mathrm{Co}, \mathrm{Ca}$ and $\mathrm{Mg}$ in the aqueous solutions were analyzed, and the concentrations of the metal ions in the loaded organic phases were determined by mass balance.

Extraction efficiency, $E$, was defined as:

$$
E=\frac{[M]_{o} V_{o}}{[M]_{o} V_{o}+[M]_{a} V_{a}} \times 100 \%
$$

whereas the separation factor of $\mathrm{Ca}$ over $\mathrm{Ni}$, $S F_{C a / N i}$, was calculated according to the distribution coefficient of the extracted components $\left(D_{M}\right)$ :

$$
\begin{gathered}
D_{M}=\frac{[\mathrm{M}]_{o}}{[M]_{a}} \times \frac{V_{o}}{V_{a}} \\
S F_{C a / N i}=\frac{D_{C a}}{D_{N i}}
\end{gathered}
$$

where $[M]_{o}$ and $[M]_{a}(\mathrm{~g} / \mathrm{l})$ are the concentrations of the respective metal ions in the loaded organic phase and the aqueous phase after equilibrium. $V_{o}$ and $V_{a}$ (l) are the corresponding volumes of the loaded organic phase and the aqueous phase.

In the scrubbing tests, the co-extracted metal ions were removed from the loaded organic phases using $\mathrm{H}_{2} \mathrm{SO}_{4}$ solutions with a range of concentrations at an aqueous-to-organic phase $(A / O)$ ratio of $1: 1$ and a temperature of $25^{\circ} \mathrm{C}$. All the systems were reacted for $10 \mathrm{~min}$, and the results from preliminary experiments indicated that this duration was sufficient to establish equilibrium conditions.

\section{Characterization Methods}

The concentrations of the metal ions within the solid products (dissolved with aqua regia) and the aqueous solutions were determined using either inductively coupled plasma-optical emission spectroscopy (ICP-OES, PerkinElmer Optima 7100 DV, USA) or atomic adsorption spectroscopy (FAAS, Varian AA240). The solid products were also characterized by XRD (PANalytical X'Pert Pro Powder, The Netherlands) and SEM (LEO 1450, Carl Zeiss Microscopy GmbH, Germany).

\section{RESULTS AND DISCUSSION}

\section{Concentration Behaviors of the Metal Ions}

The plots in Fig. 2a-d display the concentration behaviors of the metal ions during evaporation. Figure $2 \mathrm{a}$ shows that the concentrations of $\mathrm{Ni}, \mathrm{Co}$ and $\mathrm{Mg}$ increase exponentially as the solution becomes more concentrated, whereas, in contrast, the concentration of $\mathrm{Ca}$ is observed to continuously decrease, for example, the solution at $X_{V i / V r}=$ 6-comprised of $89.2 \mathrm{~g} / \mathrm{l} \mathrm{Ni}, 4.3 \mathrm{~g} / \mathrm{l} \mathrm{Co}, 0.6 \mathrm{~g} / \mathrm{l} \mathrm{Ca}$ and $7.7 \mathrm{~g} / \mathrm{l} \mathrm{Mg}$ - has an $\sim 80 \%$ precipitation yield of Ca. Further concentration to an $X_{V i / V r}$ value of 8 results in a solution with $114.5 \mathrm{~g} / \mathrm{l} \mathrm{Ni}, 5.2 \mathrm{~g} / \mathrm{l} \mathrm{Co}$, $0.6 \mathrm{~g} / \mathrm{l} \mathrm{Ca}$ and $9.0 \mathrm{~g} / \mathrm{l} \mathrm{Mg}$ and precipitation yield of $\mathrm{Ca}=87 \%$ (as shown in Fig. 2b). These results indicate that $\mathrm{Ca}$ can be readily separated from the solution because of its low solubility. ${ }^{24}$ Figure 2c presents the chord length counts recorded during the evaporation period, as determined by the Particle Track system. As can be observed, the counts of chord length $<10 \mu \mathrm{m}$ begin to increase at the $X_{V i}$ / $V r$ of ca. $\sim 2$ after $1.6 \mathrm{~h}$, which indicates the nucleation of solid particles. With longer experimental time, the counts of $<10 \mu \mathrm{m}$ and $10-100 \mu \mathrm{m}$ 
(a)

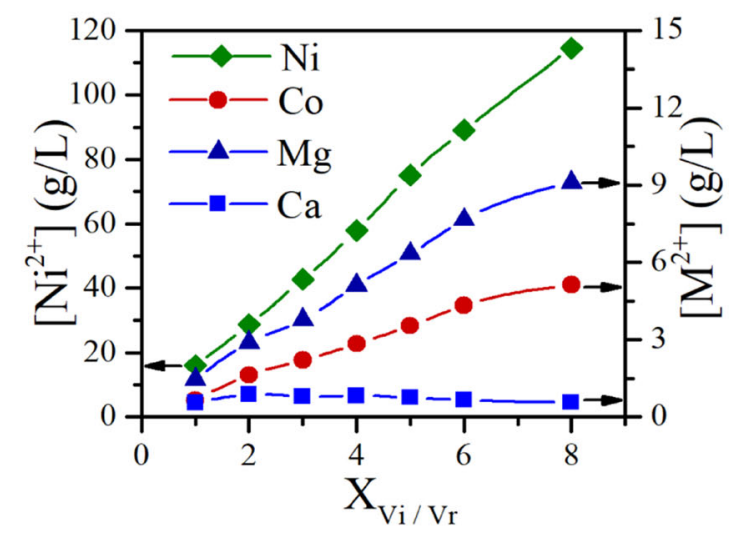

(c)

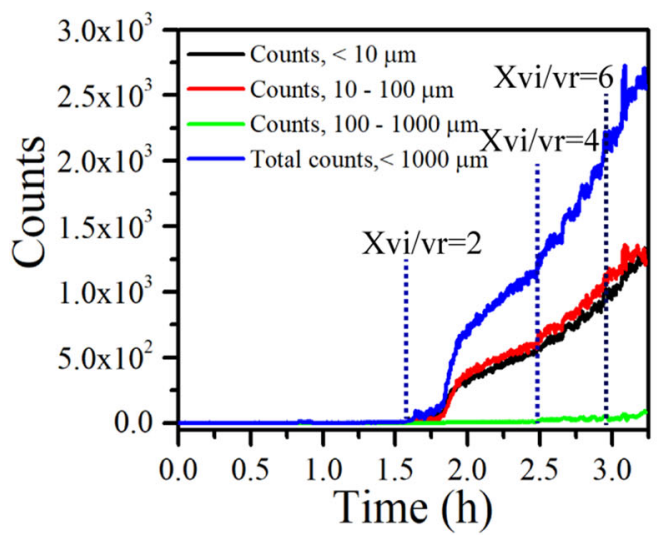

(b)

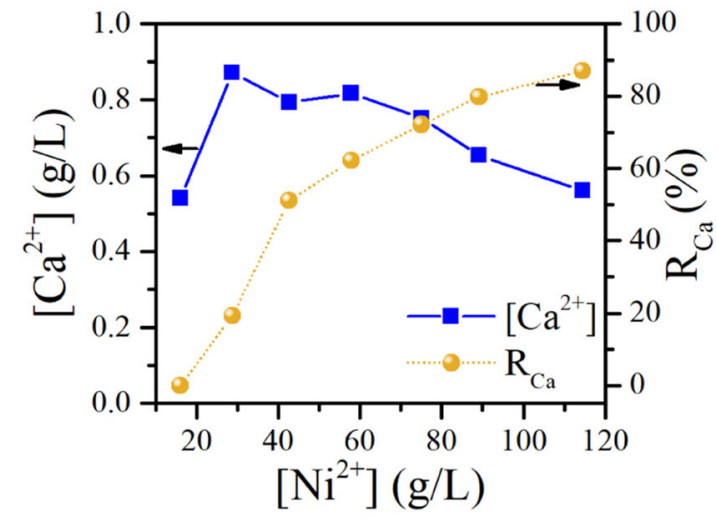

(d)

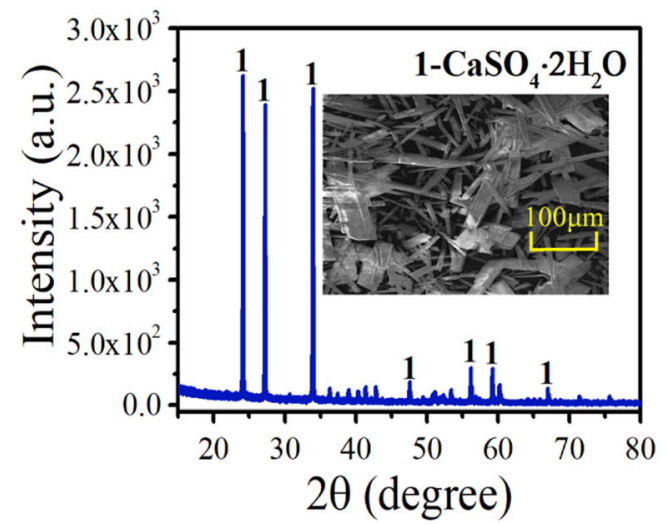

Fig. 2. (a) Concentration of the metal ions at different $X_{V i V}$; (b) precipitation yield of Ca against Ni concentration; (c) particle counts against evaporation time; (d) XRD pattern and SEM image of the solid precipitate.

continue to rise rapidly, demonstrating that both nucleation and solid crystal growth increase during the evaporation period.

The solid precipitate obtained at $X_{V i / V r}=8$ was separated and washed with the deionized water three times. Analysis of the washing water showed that it contained $5.9 \mathrm{~g} / \mathrm{l} \mathrm{Ni}, 0.3 \mathrm{~g} / \mathrm{l} \mathrm{Co}, 0.2 \mathrm{~g} / \mathrm{l} \mathrm{Ca}$ and $0.6 \mathrm{~g} / \mathrm{l} \mathrm{Mg}$, which was slightly more dilute compared with the PLS1; however, it was possible to recycle this solution back to the evaporation stage. The contents of $\mathrm{Ni}, \mathrm{Mg}$ and $\mathrm{Co}$ in the washed solid precipitate were determined to be $3.2 \%(\mathrm{~g} / \mathrm{g}), 0.3 \%$ $(\mathrm{g} / \mathrm{g})$ and $0.7 \%(\mathrm{~g} / \mathrm{g})$, respectively, which implied that only $0.3 \% \mathrm{Ni}, 0.3 \% \mathrm{Mg}$ and $1.6 \%$ Co were lost within the calcium precipitate. Subsequent analysis of the solid precipitate by XRD and SEM (Fig. 2d) confirmed that the main phase present in the solid precipitate was composed of $\mathrm{CaSO}_{4} \cdot 2 \mathrm{H}_{2} \mathrm{O}$.

\section{Selective Extraction of $\mathrm{Ca}$ with $\mathrm{Na}-\mathrm{D}_{2}$ EHPA}

The concentrated solution (PLS2) that originated from evaporation up to $X_{V i / V r}=6(89.2 \mathrm{~g} / 1 \mathrm{Ni}, 4.3 \mathrm{~g} /$ $1 \mathrm{Co}, 0.6 \mathrm{~g} / \mathrm{l} \mathrm{Ca}$ and $7.7 \mathrm{~g} / \mathrm{Mg}$ ) was used for the investigation of residual Ca removal. The effects of the extraction parameters, including equilibrium
$\mathrm{pH}$ value $\left(p H_{e q}\right)$ and the concentration of the extractant Na-D ${ }_{2}$ EHPA, were evaluated with an $\mathrm{O} / \mathrm{A}$ ratio of $1: 1$ at $25^{\circ} \mathrm{C}$. As shown in Fig. 3a, the extraction order of the metal ions follows $\mathrm{Ca}>$ $\mathrm{Mg}>\mathrm{Co}>\mathrm{Ni}$, and these findings are consistent with results reported previously. ${ }^{25,26}$ At $p H_{e q}=1.6$, the extraction efficiency of $\mathrm{Ca}$ with 20 vol.\% Na$\mathrm{D}_{2} \mathrm{EHPA}$ was found to be $74 \%$, and this was seen to increase until a maximum of 93\% at $p H_{e q}=3.0$. Over this same $p H_{e q}$ range, the respective extraction efficiencies of $\mathrm{Mg}$ changed from $7 \%$ to $23 \%$ and Co from $1 \%$ to $13 \%$, while the $\mathrm{Ni}$ extraction remained negligible $(<2 \%)$. When $\mathrm{pH}_{e q} \geq 3$, the extraction of $\mathrm{Ni}, \mathrm{Co}$ and $\mathrm{Mg}$ increased, whereas the extraction of $\mathrm{Ca}$ decreased slightly as a consequence of the crowding out effect of $\mathrm{Ni}^{27}$ The results in Fig. $3 \mathrm{~b}$ reveal that after a single contact with 10 vol. $\% \mathrm{Na}-\mathrm{D}_{2}$ EHPA at a $p H_{e q}=2.5,>89 \%$ of $\mathrm{Ca}$ can be extracted, while the extractions of $\mathrm{Mg}(10.5 \%)$, $\mathrm{Co}(7.2 \%)$ and $\mathrm{Ni}(0.6 \%)$ are much lower, leading to an associated $S F_{C a / N i}$ of 1267 . With the increase of $\mathrm{pH}_{e q}$ to 3 , approximately $91 \% \mathrm{Ca}, 16 \% \mathrm{Mg}, 8 \% \mathrm{Co}$ and $1 \% \mathrm{Ni}$ were extracted. Consequently, 10 vol.\% $\mathrm{Na}-\mathrm{D}_{2} \mathrm{EHPA}$ and $\mathrm{pH}_{e q}=2.5$ were chosen as the optimum conditions. The resultant Ca-free solution (PLS 3)—with a composition of $88.7 \mathrm{~g} / \mathrm{l} \mathrm{Ni}, 0.06 \mathrm{~g} / \mathrm{l}$ 
(a)

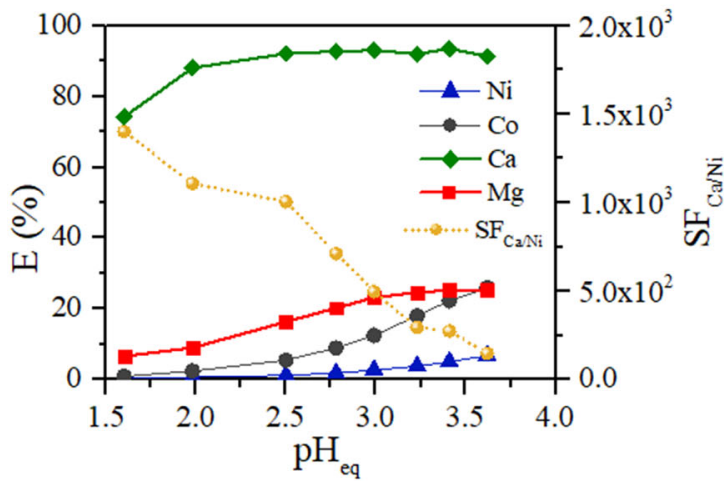

(b)

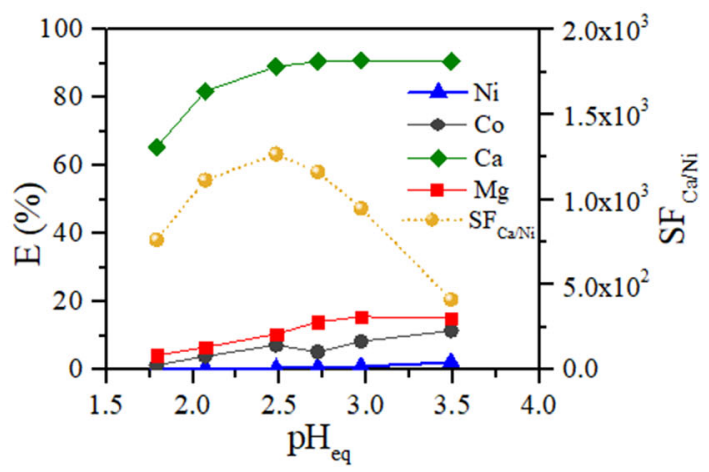

Fig. 3. Effect of the equilibrium $\mathrm{pH}$ on the extraction efficiencies and $S F_{C a / M g}$ with (a) 20 vol.\% and (b) 10 vol. $\%$ Na-D ${ }_{2}$ EHPA.

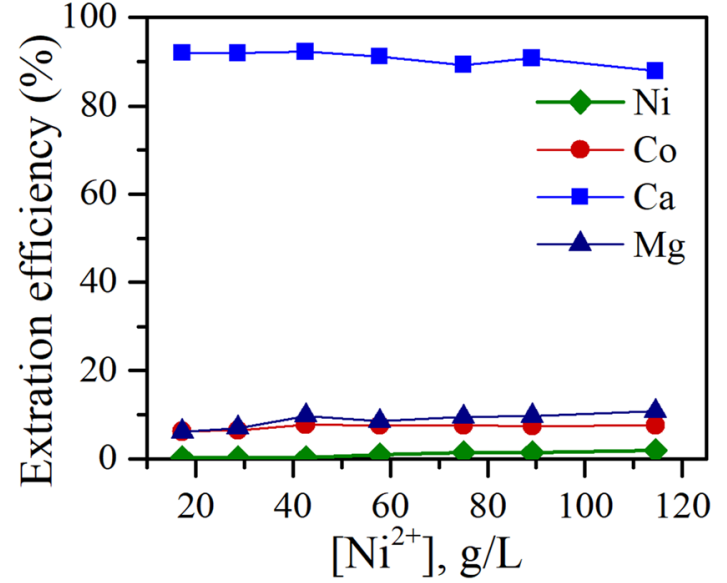

Fig. 4. Effect of $\left[\mathrm{Ni}^{2+}\right]$ of the concentrated solutions on the selective extraction of $\mathrm{Ca}$ with 10 vol. $\% \mathrm{Na}-\mathrm{D}_{2} \mathrm{EHPA}$.

$\mathrm{Ca}, 4.0 \mathrm{~g} / \mathrm{l}$ of $\mathrm{Co}$ and $7.0 \mathrm{~g} / \mathrm{l}$ of $\mathrm{Mg}$ - was used in the subsequent experiments.

The concentrated solutions with different initial $\mathrm{Ni}$ concentrations (highlighted in Fig. 2b) were contacted with 10 vol. $\%$ Na- $D_{2}$ EHPA at $\mathrm{O} / \mathrm{A}=1: 1$, $p H_{e q} \sim 2.5$ and $T=25^{\circ} \mathrm{C}$, and the corresponding extraction efficiencies of the metal ions are shown in Fig. 4. A slight decrease of the extraction efficiency of Ca from $\sim 92 \%$ to $\sim 88 \%$ can be observed as the initial Ni concentration increases from $16.3 \mathrm{~g} /$ $\mathrm{l}$ to $114.5 \mathrm{~g} / \mathrm{l}$. A similar outcome was obtained at $X_{V i / V r}=8$, where $2 \% \mathrm{Ni}, 8 \%$ Co and $11 \% \mathrm{Mg}$ were co-extracted into the loaded $\mathrm{D}_{2}$ EHPA. The results suggested that the residual Ca could be selectively extracted, as after extraction, the raffinate was found to have only $60 \mathrm{mg} / \mathrm{l}$ to $70 \mathrm{mg} / \mathrm{l} \mathrm{Ca}$ over the concentration range tested.

\section{Scrubbing of the Loaded $\mathrm{D}_{2}$ EHPA}

The scrubbing/stripping behavior of the metal ions from the loaded $\mathrm{D}_{2} \mathrm{EHPA}$ - which contained $1.2 \mathrm{~g} / \mathrm{l} \mathrm{Ni}, 0.3 \mathrm{~g} / \mathrm{l} \mathrm{Co}, 0.6 \mathrm{~g} / \mathrm{l} \mathrm{Ca}$ and $0.7 \mathrm{~g} / \mathrm{l} \mathrm{Mg}$-was studied by varying the $\mathrm{H}_{2} \mathrm{SO}_{4}$ concentration from 0 to $1 \mathrm{M}$ at $\mathrm{O} / \mathrm{A}=1: 1$ and $\mathrm{T}=25^{\circ} \mathrm{C}$. The scrubbing efficiencies of both $\mathrm{Ni}$ and Co were enhanced as the concentration of $\mathrm{H}_{2} \mathrm{SO}_{4}$ was increased from $0.01 \mathrm{M}$ to $0.05 \mathrm{M}(49 \%$ to $95 \%$ for $\mathrm{Ni}$ and $48 \%$ to $84 \%$ for $\mathrm{Co}$ ). These findings show that $\mathrm{Ni}$ and $\mathrm{Co}$ can be selectively scrubbed from the loaded $\mathrm{D}_{2} \mathrm{EHPA}$ with low $\mathrm{H}_{2} \mathrm{SO}_{4}$ concentrations (Fig. 5a), i.e., using $0.025 \mathrm{M} \mathrm{H}_{2} \mathrm{SO}_{4}$, results in a solution with $1.0 \mathrm{~g} / \mathrm{l}$ $\mathrm{Ni}, 0.25 \mathrm{~g} / \mathrm{l} \mathrm{Co}$ and $0.3 \mathrm{~g} / \mathrm{l} \mathrm{Mg}$ (PLS4). With higher concentrations of $\mathrm{H}_{2} \mathrm{SO}_{4}$, Ca can be also stripped, for example, $1.0 \mathrm{M} \mathrm{H}_{2} \mathrm{SO}_{4}$ is shown to increase $\mathrm{Ca}$ yield to $\sim 90 \%$ (Fig. 5a). Use of more concentrated $\mathrm{H}_{2} \mathrm{SO}_{4}$ enhances Ca precipitation as gypsum, especially with higher O/A ratios ( $>2: 1$ ). Therefore, based on the literature, the $\mathrm{HCl}$ solution can be suggested as an optional reagent for $\mathrm{Ca}$ stripping from the loaded organic phase and to regenerate the $\mathrm{D}_{2}$ EHPA. $^{21}$

\section{Selective Extraction of $\mathrm{Co}$ and $\mathrm{Mg}$ with Na-Cyanex 272}

The scrubbing solution (PLS4) from the loaded $\mathrm{D}_{2}$ EHPA was integrated into the Ca-free solution (PLS3) for the recovery of $\mathrm{Ni}$ and $\mathrm{Co}^{21}$ Nevertheless, the volume of the scrubbing solution that can be added is dependent on the Ni concentration of the feeding solutions used in the second extraction step. In the case detailed here, a combination of the PLS3 $(\sim 80$ vol. \%) and the PLS4 $(\sim 20$ vol.\%) resulted in a feedstock (PLS5) that contained approximately $67.5 \mathrm{~g} / \mathrm{l} \mathrm{Ni}, 3.8 \mathrm{~g} / \mathrm{l} \mathrm{Co}$ and $6.3 \mathrm{~g} / \mathrm{l} \mathrm{Mg}$. The $\mathrm{pH}$ of PLS5 was adjusted to around 5.5 with $10 \mathrm{M} \mathrm{NaOH}$ before being treated with $\mathrm{Na}-\mathrm{Cyanex} 272$ to extract $\mathrm{Co}$ and $\mathrm{Mg}{ }^{26}$ The effects of $p H_{e q}$ and Na-Cyanex 272 concentration on the extraction efficiencies of $\mathrm{Co}$, $\mathrm{Mg}$ and $\mathrm{Ni}$ were examined as detailed in Fig. 6 . From Fig. 6a, the extraction efficiencies of $\mathrm{Co}$ and $\mathrm{Mg}$ gradually increase with the increase of $p H_{e q}$. When the $p H_{e q}$ value is $<5.2$, the extraction efficiencies of $\mathrm{Co}$ and $\mathrm{Mg}$ are $<95 \%$ and $44 \%$, respectively, whereas the $\mathrm{Ni}$ extraction is $<2 \%$. $\mathrm{Mg}$ appears to be difficult to extract compared with Co, which is in accordance with the relative order of extraction selectivity previously determined for 
(a)

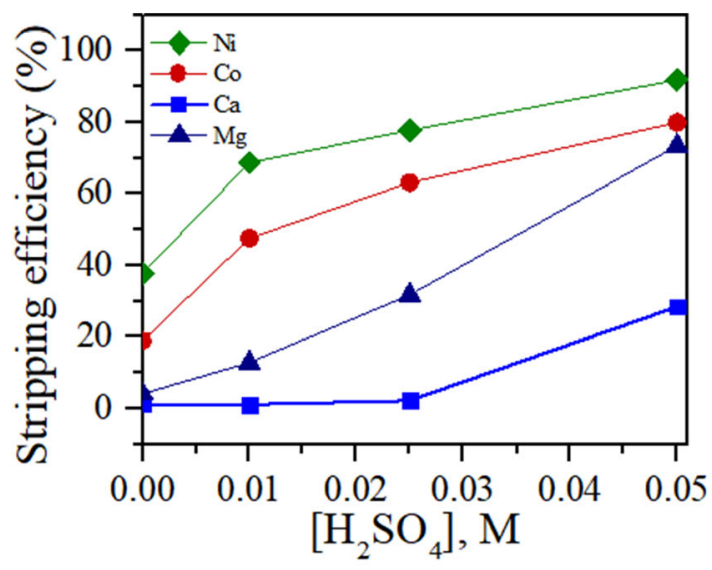

(b)

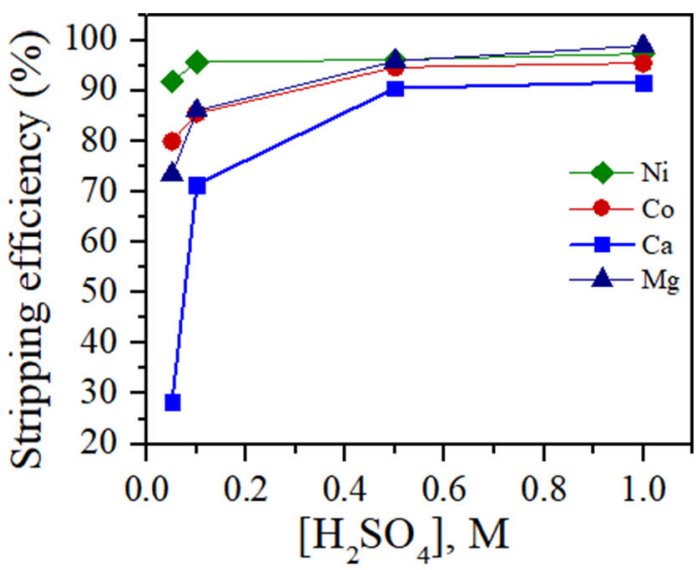

Fig. 5. Scrubbing of metals from the loaded $\mathrm{D}_{2}$ EHPA using $\mathrm{H}_{2} \mathrm{SO}_{4}$ solutions with concentrations of (a) $0-0.05 \mathrm{M}$ and (b) $0.05-1.0 \mathrm{M}$.

(a)

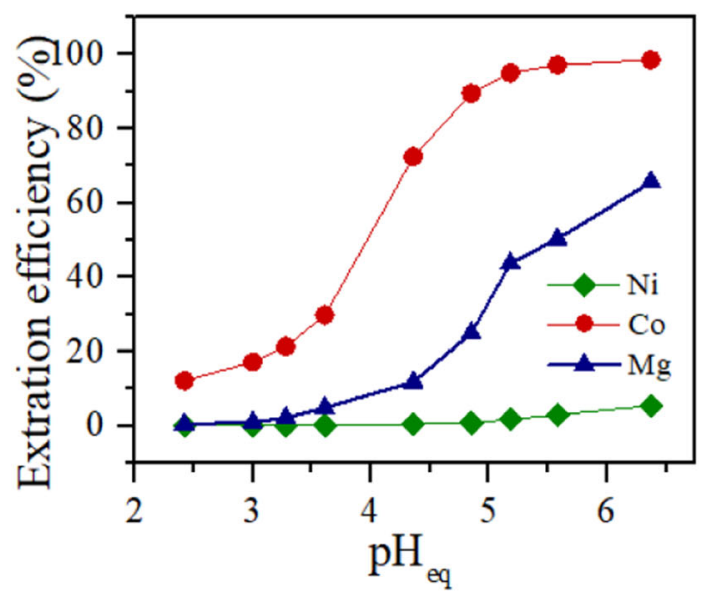

(b)

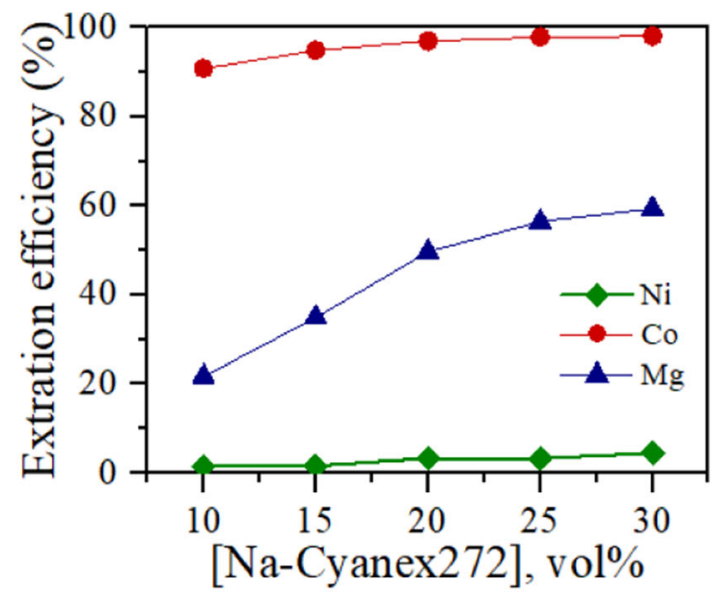

Fig. 6. Effect of (a) $\mathrm{pH}_{e q}$ and (b) Na-Cyanex 272 concentration (at $p H_{e q} \sim 5.5$ ) on the extraction efficiencies of $\mathrm{Ni}$, Co and $\mathrm{Mg}$.

Cyanex 272. ${ }^{28}$ A further increase in $\mathrm{pH}_{e q}$ to 5.6 gives rise to extraction efficiencies of $\sim 97 \%$ Co and $51 \% \mathrm{Mg}$; however, crud begins to be observed when the $p H_{e q}$ is $>6.3$. The formation of crud within the solution at elevated $p H_{e q}$ is believed to result from the formation of insoluble $\mathrm{Ni}(\mathrm{OH})_{2}$, as proposed by both Cheng et al. ${ }^{29}$ and Guimarães et al. ${ }^{21,30} \mathrm{In}$ Fig. $6 \mathrm{~b}$, the increase in the concentration of $\mathrm{Na}$ Cyanex 272 from 10 vol.\% to 30 vol.\% at $p H_{e q} \sim 5.5$ results in an increase in the extraction of all metal ions, especially $\mathrm{Mg}$. Nevertheless, the extraction efficiency of $\mathrm{Ni}$ is relatively high at $\sim 5 \%$ with 30 vol.\% Na-Cyanex 272. Consequently, 20 vol.\% NaCyanex 272 was determined to be the optimum level required to selectively extract $\mathrm{Co}$ and $\mathrm{Mg}$.

The isotherms of $\mathrm{Co}$ and $\mathrm{Mg}$ extractions were evaluated at varying $\mathrm{A} / \mathrm{O}$ ratios $(2: 1,1: 1,1: 2,1: 3,1: 4$ and 1:5) by exposing the mixed solution (PLS5) to a single contact with 20 vol.\% Na-Cyanex 272. The extraction distribution isotherms and their McCabe-
Thiele diagrams are displayed in Fig. 7a and b. The results in Fig. 7 a show that at the A/O ratio of $1: 1$, two theoretical stages are required to extract $\sim 100 \%$ Co, whereas Fig. 7b highlights that two theoretical extraction stages at the $\mathrm{A} / \mathrm{O}$ ratio of $1: 2$ are needed to extract $\sim 95 \% \mathrm{Mg}$. It is worth noting that with the increase in the O/A ratio, the coextraction of $\mathrm{Ni}$ becomes significantly higher as more extraction sites are freely available. Therefore, for the successful separation of $\mathrm{Co}$ and $\mathrm{Mg}$ vs. $\mathrm{Ni}$, the $\mathrm{O} / \mathrm{A}$ ratio plays a crucial role. ${ }^{32} \mathrm{~A}$ lower O/A ratio (1:1) with an additional extraction stage can be used to suppress $\mathrm{Ni}$ co-extraction and ensure efficient $\mathrm{Mg}$ separation. Use of an O/A ratio of 2:1 in the first stage, followed by two subsequent stages at an O/A ratio of $1: 1$, resulted in a raffinate (PLS6) that contained $61.7 \mathrm{~g} / \mathrm{l} \mathrm{Ni}, 0.007 \mathrm{~g} / \mathrm{l} \mathrm{Co}$ and $0.3 \mathrm{~g} / \mathrm{l} \mathrm{Mg}$, which is of an acceptable purity and concentration to be used as a feedstock for state-of-the-art hydrometallurgical high-purity $\mathrm{Ni}$ recovery processes. ${ }^{31,32}$ 
(a)

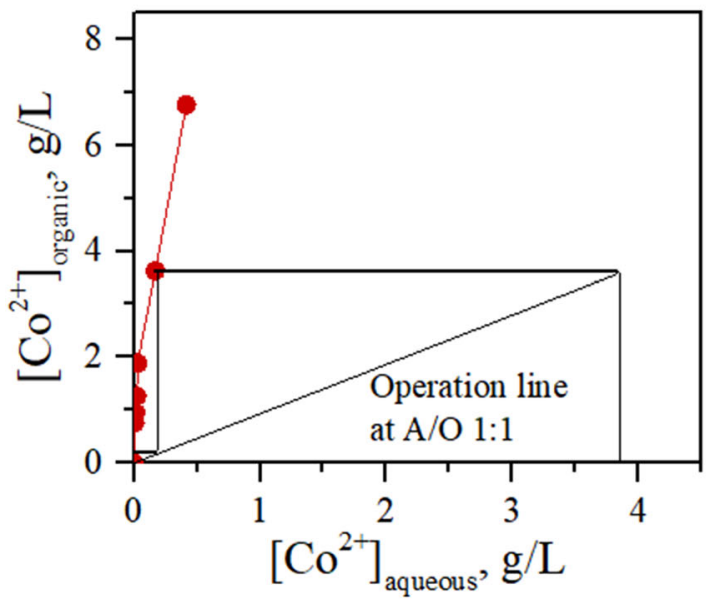

(b)

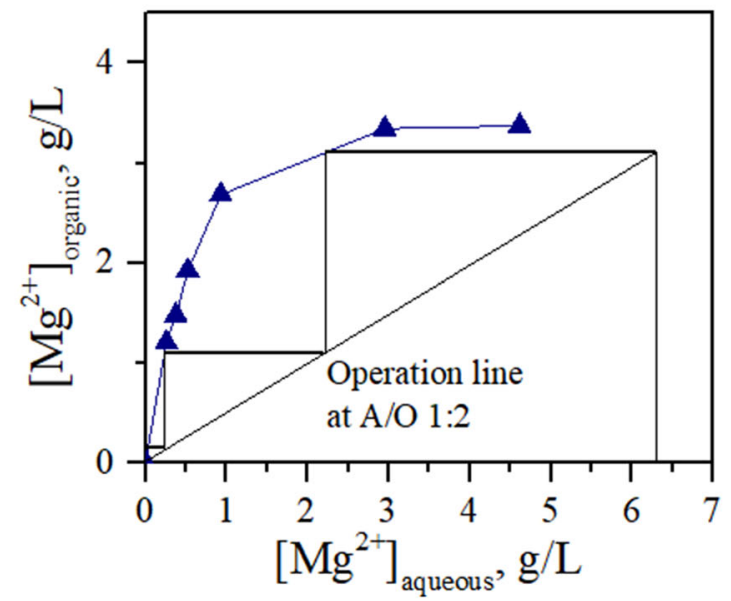

Fig. 7. McCabe-Thiele diagrams for (a) Co and (b) Mg extractions with 20 vol.\% Na-Cyanex 272.

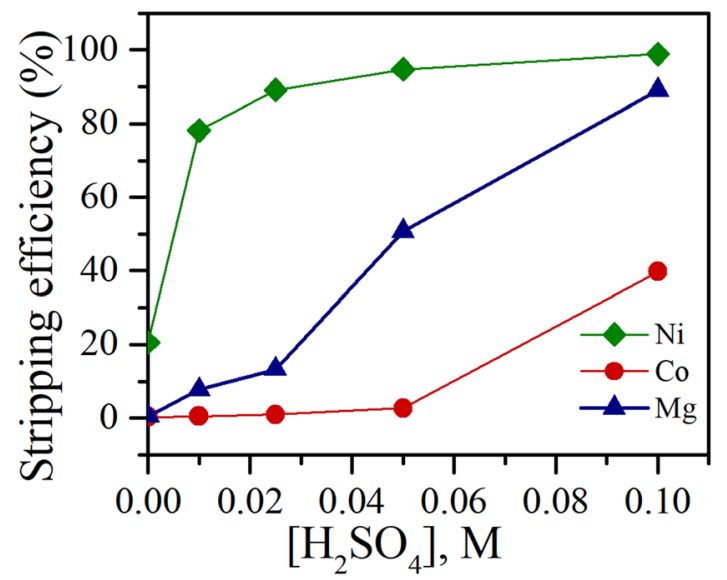

Fig. 8. Scrubbing of $\mathrm{Ni}$, Co and $\mathrm{Mg}$ from the loaded Cyanex 272 using $\mathrm{H}_{2} \mathrm{SO}_{4}$ solutions with concentrations of $0-0.1 \mathrm{M}$.

\section{Scrubbing of the Loaded Cyanex 272}

The scrubbing behavior of $\mathrm{Ni}, \mathrm{Co}$ and $\mathrm{Mg}$ from the loaded Cyanex 272-which contained $1.4 \mathrm{~g} / \mathrm{l} \mathrm{Ni}$, $3.5 \mathrm{~g} / \mathrm{l} \mathrm{Co}$ and $2.8 \mathrm{~g} / \mathrm{l} \mathrm{Mg}$-were studied with different concentrations $(0-0.1 \mathrm{M})$ of $\mathrm{H}_{2} \mathrm{SO}_{4}$ solution. As shown in Fig. 8, with a $0.025 \mathrm{M} \mathrm{H}_{2} \mathrm{SO}_{4}$ solution, approximately $91 \% \mathrm{Ni}$ and $13 \% \mathrm{Mg}$ can be selectively scrubbed, while only $1 \%$ Co is removed from the loaded Cyanex 272. When $0.05 \mathrm{M} \mathrm{H}_{2} \mathrm{SO}_{4}$ is used, the scrubbing efficiency of $\mathrm{Mg}$ increases significantly to around 50\%, whereas the associated efficiencies of $\mathrm{Ni}$ and Co increase to $97 \%$ and $3 \%$, respectively. Accordingly, the $\mathrm{H}_{2} \mathrm{SO}_{4}$ concentration for the selective scrubbing $\mathrm{Ni}$ from the loaded Cyanex 272 was chosen as $0.025 \mathrm{M}$ to minimize impurities in the resultant $\mathrm{Ni}$ solution. After the selective scrubbing of $\mathrm{Ni}$, the loaded Cyanex 272 can be further scrubbed to produce a relatively Co-rich strip solution that can then be treated via sulfide precipitation to recover the Co. ${ }^{33,34}$

\section{CONCLUSION}

To enhance the purity and increase the value of an underutilized industrial sidestream, a combined evaporation and solution purification method was investigated. Results showed that when the concentration degree was $X_{V i / V r} \geq 6$, at least $80 \%$ of $\mathrm{Ca}$ impurities could be precipitated as $\mathrm{CaSO}_{4} \cdot 2 \mathrm{H}_{2} \mathrm{O}$ with minimal associated losses $(0.3 \% \mathrm{Ni}, 0.3 \% \mathrm{Mg}$ and $1.6 \% \mathrm{Co}$ ). Residual impurities were then effectively removed by solvent extraction with Na$\mathrm{D}_{2}$ EHPA (10 vol.\% Na- $\mathrm{D}_{2}$ EHPA, O/A ratio of $1: 1$ and $\mathrm{pH}_{e q}$ of 2.5 at $25^{\circ} \mathrm{C}$ ), and any co-extracted $\mathrm{Ni}$ and $\mathrm{Co}$ were recovered by selective scrubbing $\left(0.025 \mathrm{M} \mathrm{H}_{2} \mathrm{SO}_{4}\right)$ before being re-integrated back into the process. Finally, the use of a three-stage solvent extraction by Na-Cyanex 272 (20 vol.\% NaCyanex 272, first stage at an $\mathrm{O} / \mathrm{A}$ ratio of $2: 1$ and two further stages at an O/A ratio of $1: 1, \mathrm{pH}_{e q} \sim 5.7$ at $25^{\circ} \mathrm{C}$ ) demonstrated that a high-purity Ni-rich solution could be produced from the initial sidestream. As a result, the application of a concentration and multi-step solvent extraction combination has the potential to simultaneously valorize lowgrade solutions, reduce waste and enhance the metal's circular economy.

\section{ACKNOWLEDGEMENTS}

Open access funding provided by Aalto University. This work was supported financially by the BATCircle project (Grant No. 4853/31/2018) funded by Business Finland and the Chinese Scholar Council (CSC). The authors appreciate the use of facilities provided by the Academy of Finland's RawMatTERS Finland Infrastructure (RAMI-FIRI) based at Aalto University and also thank Hannu Revitzer for performing the ICP analyses. In addition, the Anhui Province Research and Development Innovation Project for Automotive Power Battery Efficient Recycling Systems is gratefully acknowledged. 


\section{OPEN ACCESS}

This article is distributed under the terms of the Creative Commons Attribution 4.0 International License (http://creativecommons.org/licenses/by/4.0/), which permits unrestricted use, distribution, and reproduction in any medium, provided you give appropriate credit to the original author(s) and the source, provide a link to the Creative Commons license, and indicate if changes were made.

\section{REFERENCES}

1. V. Coman, B. Robotin, and P. Ilea, Resour. Conserv. Recy. 73, 229 (2013).

2. B.P. Wilson, N.P. Lavery, D.J. Jarvis, T. Anttila, J. Rantanen, S.G.R. Brown, and N.J. Adkins, J. Power Sources 243, $242(2013)$

3. P. Meshram, Abhilash and B.D. Pandey, Min. Proc. Ext. Met. Rev. 40, 157 (2019).

4. C. Sist and G.P. Demopoulos, JOM 55, 42 (2003).

5. R. Harvey, R. Hannah, and J. Vaughan, Hydrometallurgy 105, 222 (2011).

6. K.C. Sole, M.B. Mooiman, and E. Hardwick, Sep. Purif. Rev. 47, 159 (2018).

7. Z. Zainol and M.J. Nicol, Hydrometallurgy 175, 99 (2009).

8. I. Van De Voorde, L. Pinoy, and R.F. De Ketelaere, J. Membrane Sci. 234, 11 (2004).

9. K.C. Sole, A.M. Feather, and P.M. Cole, Hydrometallurgy $78,52(2005)$.

10. V. Kumar, S.K. Sahu, and B.D. Pandey, Hydrometallurgy 103, 45 (2010).

11. B. Han, O. Bockman, B.P. Wilson, M. Lundström, and M. Louhi-Kultanen, Chem. Eng. Technol. 42, 1475 (2019).

12. G.A. Moldoveanu and G.P. Demopoulos, JOM 54, 49 (2002).

13. C. Lupi, M. Pasquali, and A. Dell'Era, Miner. Eng. 19, 1246 (2006)

14. R.R. Moskalyk and A.M. Alfantazi, Miner. Eng. 15, 593 (2002)

15. A. Feather, W. Bouwer, A. Swarts, and V. Nagel, J.S. Afr. I Min. Metall. 102, 457 (2002).

16. C.Y. Cheng and M. Urbani, P. ISEC, (2005) pp 503-526.
17. P.M. Cole, K.C. Sole, and A.M. Feather, Tsingha. Sci. Technol. 153, 11 (2006).

18. M. Mackenzie, M. Virnig, and A. Feather, Miner. Eng. 19, 1220 (2006).

19. S. Donegan, Miner. Eng. 19, 1234 (2006).

20. A.S. Guimarães, P.S. da Silva, and M.B. Mansur, Hydrometallurgy 150, 173 (2014).

21. A.S. Guimarães and M.B. Mansur, Hydrometallurgy 173, 91 (2017).

22. D. Mohapatra, K. Hong-In, C.W. Nam, and K.H. Park, Sep. Purif. Technol. 56, 311 (2007).

23. N.B. Devi, K.C. Nathsarma, and V. Chakravortty, Hydrometallurgy 49, 47 (1998).

24. W.M. Hayes and D.R. Lide, Aqueous solubility of inorganic compounds at various temperatures. CRC Handbook of Chemistry and Physics, $92^{\text {nd }}$ Edition. CRC Press LLC, Boca Raton, USA, 5-190 (2011).

25. C.Y. Cheng, Hydrometallurgy 56, 369 (2000).

26. H. Bukowsky, E. Uhlemann, K. Gloe, and P. Mühl, Hydrometallurgy 28, 323 (1992).

27. M.F. Souza and M.B. Mansur, Braz. J. Chem. Eng. 36, 541 (2019).

28. K.C. Sole, The evolution of cobalt-nickel separation and purification technologies: fifty years of solvent extraction and ion exchange (The Minerals: Metals \& Materials Series. Springer, 2018)

29. C.Y. Cheng, G. Boddy, W. Zhang, M. Godfrey, D.J. Robinson, Y. Pranolo, Z. Zhu, L. Zeng, and W. Wang, Hydrometallurgy 104, 53 (2010).

30. A.S. Guimarães and M.B. Mansur, Hydrometallurgy 250, 175 (2018)

31. Z.W. Zhu, J. Zhang, A.F. Yi, H. Su, L. Wang, and T. Qi, IJMPEM 36, 4 (2019).

32. V. Agarwal, M.K. Khalid, A. Porvali, B.P. Wilson, and M. Lundström, Sust. Mater. Tech 22, e00121 (2019).

33. V. Meeyoo, A.A. Adesina, and G. Foulds, Chem. Eng. Commun. 144, 1 (1996).

34. F.K. Crundwell, M.S. Moats, V. Ramachandran, T.G. Robinson and W.G. Davenport. Extractive Metallurgy of Nickel, Cobalt and Platinum Group Metals. Elsevier, UK, 117-122 (2011)

Publisher's Note Springer Nature remains neutral with regard to jurisdictional claims in published maps and institutional affiliations. 